\title{
Phase II trial of second-line erlotinib and digoxin for nonsmall cell lung cancer (NSCLC)
}

This article was published in the following Dove Press journal:

Open Access Journal of Clinical Trials

4 February 201 I

Number of times this article has been viewed

\section{Fadi Kayali \\ Muhamad A Janjua \\ Damian A Laber \\ Donald Miller \\ Goetz H Kloecker}

University of Louisville, James Graham Brown Cancer Center, Louisville, KY, USA
Correspondence: Goetz H Kloecker University of Louisville, 529 S. Jackson Street, Louisville, KY 40202, USA

Tel +l 5025624358

Fax + I $50256268 \mid$ I

Email ghkloe0I@louisville.edu; goetzkloecker@yahoo.com
Background: In vitro digoxin sensitizes cancer cells to the induction of apoptosis by chemotherapy. Inhibition of the $\mathrm{Na} / \mathrm{K}$-ATPase enzyme by ouabain disturbs the intracellular ion composition of cancer cells, altering cellular homeostasis. This suggests that inhibition of the $\mathrm{Na} / \mathrm{K}$ pump results in cellular sensitization of malignant but not benign cells to the induction of apoptosis. Epidemiologic studies have also shown beneficial effects of digitalis in breast cancer incidence. At ASCO (American Society of Clinical Oncology) 2007 our group presented a Phase II study showing encouraging results by adding digoxin to biochemotherapy for melanoma. Erlotinib is one of the standard second-line treatments for nonsmall cell lung cancer (NSCLC), with a response rate (RR) of $10 \%$. This study's hypothesis was that adding digoxin to erlotinib will improve the RR and time to progression (TTP) in NSCLC.

Methods: Patients with progressive disease (PD) after chemotherapy were enrolled if they had an ECOG (Eastern Cooperative Oncology Group) score from 0 to 2 and good organ function. Daily erlotinib $150 \mathrm{mg}$ and digoxin $0.25 \mathrm{mg}$ were taken by mouth. The digoxin dose was adjusted to keep levels between 1 and $2 \mathrm{ng} / \mathrm{mL}$. Computed tomography scans were done every 6 weeks. Treatment continued until PD or significant toxicity occurred.

Results: Patient accrual lasted from March 2006 until August 2008 and was stopped early at the time of interim analysis. Twenty-eight patients were enrolled, and 24 who completed at least 6 weeks of therapy are presented here. All patients had unresectable NSCLC stage III/IV at diagnosis. Median age was 61 (34-78), 14 were female, 17 had prior radiation (not involving the target lesions), 23 had one prior chemotherapy, and one subject had two. Only one patient was a never-smoker. Histologies were 50\% adenocarcinoma, $30 \%$ squamous, and $20 \%$ unspecified. One patient had a partial response, nine had stable disease, and 14 had progressive disease. The median TTP was 61 days (9-366) and median survival 157 days (9-844). Side effects were similar to erlotinib single agent with no treatment-related mortality. There were no unexpected or increased adverse events related to digoxin.

Conclusions: Digoxin did not increase the response rate of erlotinib in the treatment of progressive NSCLC. The TTP and survival seen in this study were similar to the published results with erlotinib alone. This combination does not warrant further clinical studies in NSCLC.

Keywords: metastatic lung cancer treatment, digitalis, erlotinib

\section{Introduction}

Lung cancer (LC) is the leading cause of cancer death worldwide. In the United States alone, there are more than 200,000 new cases and almost 160,000 deaths annually. ${ }^{1}$ It remains the leading cause of cancer-related mortality in both sexes, accounting for about $30 \%$ and $25 \%$ of cancer deaths in men and women, respectively. ${ }^{1,2}$ Approximately $80 \%$ of LCs are of the nonsmall cell (NSC) histology. The majority of NSCLC has 
locally advanced stage III (30\%) or metastatic stage IV (35\%) disease at diagnosis. ${ }^{3}$

Once NSCLC has progressed or recurred after standard first-line chemotherapy with or without platinum containing agents, the choice of treatment and its efficacy becomes more limited. Until 2004, only two chemotherapy agents were approved by the United States Food and Drug Administration for second-line treatment of NSCLC, docetaxel and pemetrexed. This approval was based on randomized trials showing three months prolongation of median survival, with response rate of less than $10 \%$ for each agent and some palliative effect on lung cancer symptoms. ${ }^{4-6}$ Erlotinib is a tyrosine kinase inhibitor, which acts on the epidermal growth factor receptor (EGFR). Erlotinib was approved in 2004 for secondand third-line treatment of NSCLC based on a randomized study by the NCIC (National Cancer Institute of Canada), BR.21, which revealed a survival benefit of $10 \%$ at 1 year compared to placebo. ${ }^{6}$

There is encouraging laboratory evidence that digoxin can sensitize cancer cells to the induction of apoptosis by chemotherapeutic agents. The mechanism by which digitalis affects cancer cells is complex and involves multiple pathways, such as inhibition of angiogenesis and induction of apoptosis. ${ }^{7,8}$ Inhibition of the $\mathrm{Na}^{+} / \mathrm{K}^{+}$-ATPase enzyme by ouabain profoundly disturbs the intracellular ion composition of cancer cells, altering cellular homeostasis and induces apoptosis. ${ }^{7,9}$ This alteration in the intracellular ion concentration can result in markedly increased sensitivity to induction of chemotherapy. Also, ouabain-induced activation/transactivation of Src/EGFR by $\mathrm{Na}^{+} / \mathrm{K}^{+}$-ATPase recently has been shown to activate ERK1/2 - resulting in an increase of the level of cell cycle inhibitor p21Cip1, and growth arrest in breast cancer cells. ${ }^{10}$ Overall $\mathrm{Na}^{+} / \mathrm{K}^{+}$-ATPase activity is increased in NSCLC cells. ${ }^{11}$ The observation that binding of cardiac glycosides to $\mathrm{Na}^{+} / \mathrm{K}^{+}$-ATPase activates several signaling pathways, ${ }^{12}$ has suggested a very complex set of molecular interactions by which cardiac glycosides participate in molecular transformation.

As digoxin alters the ionic and intracellular microenvironment and induces cytotoxic effect, we thought the addition of erlotinib will have a synergistic effect through two different mechanisms on the EGFR. Nonetheless, epidemiological studies have shown beneficial effects of digitalis in breast cancer incidence and melanoma. ${ }^{13-16}$

Considering the poor response rate in the standard second-line treatment of NSCLC and the activity of digitalis on cancer cells with low rate of adverse effects and cost, we propose a Phase II trial of a combination therapy with erlotinib and digoxin in patients whose LC has progressed after first-line chemotherapy.

\section{Methods Eligibility}

All patients 18 years or older with NSCLC who failed first-line chemotherapy with at least stage IIIB disease were eligible for the study. Primary tumor must have been documented by histopathologic analysis. Other criteria included: disease recurrences occurring greater than 5 years after the original diagnosis must have been biopsy proven; treatment with only one prior chemotherapy regimen for advanced disease (one additional prior regimen was allowed for neoadjuvant, adjuvant, or neoadjuvant plus adjuvant therapy), measurable or evaluable disease; performance status (Eastern Cooperative Oncology Group [ECOG] score) of 0-3 with adequate organ function; patients must have had a computed tomography (CT) scan of the chest and abdomen within 4 weeks prior to registration.

Exclusion criteria were: any patient with history of active cardiac disease, nursing or pregnant women, or any other malignancy.

Patients were informed of the investigational nature of this study and signed and gave a written informed consent in accordance with the Declaration of Helsinki and Good Clinical Practice Guidelines and approved by the Institutional Review Board and federal guidelines.

\section{Study design and treatment}

This was a single-arm Phase II clinical trial evaluating secondline erlotinib in combination with digoxin in patients who progressed after their initial therapy. Erlotinib was given at a daily dose of $150 \mathrm{mg}$ concurrently with digoxin $0.25 \mathrm{mg}$. Each cycle was a 3-week interval, and patients continued their treatment until disease progression or the development of unacceptable toxicity. Digoxin level was checked within the first week, and if it was below therapeutic range, an extra dose of digoxin $(0.125 \mathrm{mg})$ was administered and the dose of digoxin was adjusted to maintain a therapeutic level. Thereafter, digoxin level was checked every 30 days to prevent levels beyond therapeutic range (range may differ with laboratory used) or earlier if clinically indicated. An electrocardiogram was checked prior to initiation of treatment. Electrolytes were checked and supplemented if needed.

\section{Dose modification}

If digoxin level was found to be higher than the reference range (1-2 ng/mL) or the patient developed adverse effects 
related to digoxin, the digoxin doses were held for a period of 48 hours. Digoxin level, renal function, and serum chemistry were rechecked. Digoxin was restarted once the digoxin level was in therapeutic range, and the patient's digoxin-related symptoms had resolved. Dose modification and monitoring for erlotinib-related toxicity is described elsewhere. ${ }^{6}$ Any grade 3/4 adverse effect is an unacceptable toxicity and led to withdrawal from the study.

\section{Assessment}

Tumor status was evaluated using CT every 6 weeks. Therapeutic response was assessed using RECIST (response evaluation criteria in solid tumors). Patients were removed from the study if they developed disease progression, unacceptable toxicity, and treatment delay of $>4$ weeks.

Toxicity was recorded utilizing the National Cancer Institute Common Toxicity Criteria Version 3.0. Digoxin level was evaluated 1 week after initiating treatment and then every 30 days. The digoxin dose was adjusted to keep levels between 1 and $2 \mathrm{ng} / \mathrm{mL}$. Dose modification was specified in the study protocol.

\section{Statistical methods}

The primary objective of this study was to determine the response rate of patients with progressive NSCLC treated with a regimen of erlotinib plus digoxin. This is a one-arm Phase II clinical trial that tested the hypothesis that adding digoxin to erlotinib would increase the response rate from $9 \%$ to $25 \%$. Secondary endpoint of the study was overall survival (OS) and combination of partial and complete responses $(\mathrm{PR}+\mathrm{CR})$. Stable disease and disease progression (SD+PD) were considered nonresponses for the purpose of statistical analysis. Response rate as the efficiency endpoint was used for the sample size and power estimation for this one-arm Phase II trial.

Simon presents a method for finding optimal sample sizes under the null hypothesis for two-stage designs. ${ }^{17}$ Using an alternative response rate of $25 \%$, Type I error of 0.05 and power $0.80,18$ patients were treated initially prior to an interim analysis. The interim analysis was done after the 18th patient was imaged during cycle 3 (week 7-9). If two $(11 \%)$ or fewer of these patients had a positive response, the trial was terminated. If more than 2 patients had a positive response, we continued to a total of 43 patients. Overall, if more than 7 of the 43 patients had a positive response, we concluded that the treatment was effective.

Adverse events and toxicities were summarized. Responses and adverse event rates were calculated with confidence intervals using statistical software (SPSS; SPSS INC., ... etc). Results were reported for the patient group as a whole and for the two strata (ex/active smoker and nonsmoker) as well.

Subjects were followed regarding overall survival. Kaplan-Meier survival curve estimates were computed and plotted.

\section{Results}

\section{Patient characteristics}

Patient accrual lasted from March 2006 until August 2008 and was stopped early at the time of interim analysis. Twentyfour patients were enrolled, who completed at least 6 weeks of therapy. Median age was 61 years (range 34-78), and 14 patients $(58 \%)$ were female (Table 1). All patients had unresectable stage III/IV at diagnosis and failed at least one prior chemotherapy.

\section{Treatment}

The median number of cycles delivered to the patients was six, including one patient who is still on therapy with stable disease. All patients tolerated the treatment very well without dose reduction.

Table I Patient demographics $(\mathrm{N}=24)$

\begin{tabular}{|c|c|c|}
\hline \multirow[t]{2}{*}{ Characteristic } & \multicolumn{2}{|c|}{ Patient } \\
\hline & No. & $\%$ \\
\hline Median age, years & \multicolumn{2}{|c|}{61} \\
\hline Range & \multicolumn{2}{|c|}{$34-78$} \\
\hline \multicolumn{3}{|l|}{ Sex } \\
\hline Male & 10 & 42 \\
\hline Female & 14 & 58 \\
\hline \multicolumn{3}{|l|}{ Race } \\
\hline Black & 7 & 29 \\
\hline White & 17 & 71 \\
\hline \multicolumn{3}{|l|}{ ECOG } \\
\hline 0 & I & 4 \\
\hline I & 14 & 58 \\
\hline 2 & 7 & 29 \\
\hline 3 & 2 & 8 \\
\hline \multicolumn{3}{|l|}{ Smoking } \\
\hline Active & 12 & 50 \\
\hline Previous & II & 46 \\
\hline Never & 1 & 4 \\
\hline \multicolumn{3}{|l|}{ Histology type } \\
\hline Adenocarcinoma & 9 & 38 \\
\hline Squamous & 8 & 33 \\
\hline Unknown & 7 & 29 \\
\hline Previous radiation & 24 & 100 \\
\hline \multicolumn{3}{|c|}{ Previous chemotherapy } \\
\hline I line & 22 & 92 \\
\hline 2 lines & 2 & 8 \\
\hline
\end{tabular}

Abbreviation: ECOG, Eastern Cooperative Oncology Group score. 


\section{Safety}

Most patients tolerated treatment very well with minimal side effects. Side effects were similar to erlotinib single agent with no treatment-related mortality. There were no unexpected or increased adverse events (grade 3/4) related to digoxin. Digoxin level was monitored according to study protocol and kept in the therapeutic range of $1-2 \mathrm{ng} / \mathrm{mL}$.

\section{Efficacy}

One patient had a partial response, nine patients had stable disease, and 14 patients had progressive disease. The median TTP was 61 days (9-366 days) (Figure 1). Median survival was 157 days (9-844 days). One patient continues to be on treatment with stable disease.

\section{Discussion}

This is a single-arm Phase II clinical trial evaluating the addition of digoxin to erlotinib in the treatment of patients with NSCLC who progressed after first-line therapy. Our data showed median TTP of 2 months with median OS of 5.3 months. These results did not add any clinical benefit to patients who received erlotinib alone. The addition of digoxin to erlotinib did not have any additional toxicity on the patients. A previous placebo control clinical trial that evaluated erlotinib after disease progression in patients with NSCLC showed a PFS of 2.2 months and OS of 6.7 months. ${ }^{6}$ These results were similar to our result.

Digitalis was extensively evaluated in vitro. There is no previous clinical evaluation of digitalis in NSCLC patients. Shephered et $\mathrm{l}^{6}$ found that patients with EGFR expression, never smoker, and adenocarcinoma had a better response to erlotinib. One of the limitations of this study is that this is an untested population for EGFR status, and we did not

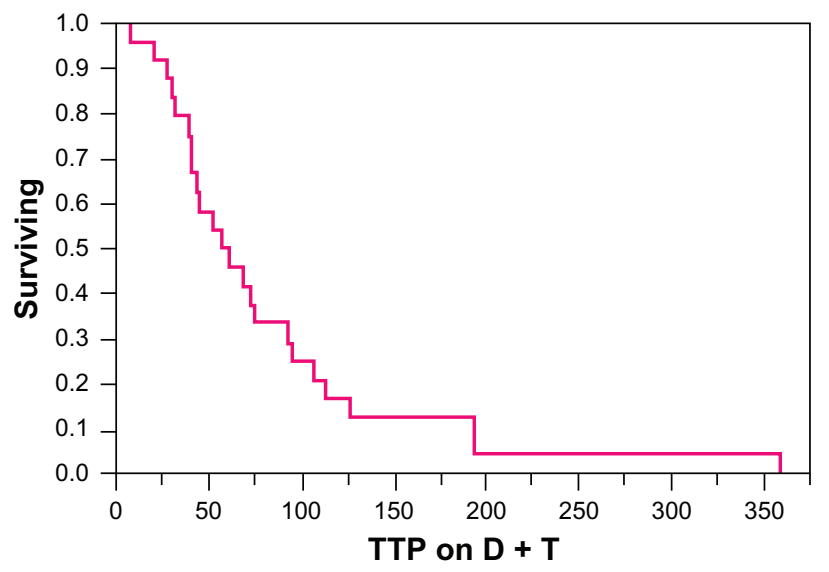

Figure I TTP of NSCLC patients on second-line treatment with erlotinib and digoxin. Abbreviations: D, Digoxin; T, Tarceva (Erlotinib); NSCLC nonsmall cell lung cancer; TTP, time to progression. stratify patients according to their EGFR status as it might have affected the response rate either for erlotinib or in combination with digoxin.

With increasing cost of the health care system and the preclinical finding that ouabian has antitumor activity through targeting $\mathrm{Na}^{+} / \mathrm{K}^{+}$-ATPase and increasing signal transduction, we believe that further evaluation and identification of more specific targets for digoxin might enhance its effect. Cardiac glycoside has been used for many years in patients with cardiac disease with a well known toxicity profile and low cost. $\mathrm{Na}^{+} / \mathrm{K}^{+}$-ATPase has four $\alpha$ subunits. In a review by Newman et al, a difference in relative expression of $\alpha$ subunit, in particular $\alpha_{1} / \alpha_{3}$ of tumor cell, might have a role in tumor cell sensitivity to different cardinolides. ${ }^{8}$ Frese et al found that LC cells are resistant to tumor necrosis factor Apo2/TRAIL that induces apoptosis in cancer but not normal cells. ${ }^{18}$ They found that adding cardiac glycosides Apo2/TRAIL increase NSCLC cell death through upregulation of death receptor DR4 and DR5, and the combination may be a new, interesting anticancer-induced apoptosis. Others have reported that higher blood level of digitalis might have a protective and/ or antitumor activity. ${ }^{16}$ Other studies, however, found the cytotoxic effect for certain cancers, eg, colon cancer, to be very dose dependent, requiring pharmacokinetic levels that may not be tolerated in clinical studies. ${ }^{19}$ Therefore, further evaluation and identification of new targets in tumor cells to evaluate their sensitivity to different cardinolides are needed. Also, in vitro evaluation of cardinolides with different antitumor drugs might be warranted to evaluate the synergistic effect of this treatment modality.

In conclusion, the addition of digoxin did not add any clinical benefit to erlotinib, and this combination does not warrant further clinical studies in NSCLC. Further clinical and preclinical studies are warranted to evaluate better target and chemotherapeutic combination with digoxin.

\section{Disclosure}

The authors report no conflicts of interest in this work.

\section{References}

1. Jemal A, Siegel R, Ward E, Hao Y, Xu J, Thun MJ. Cancer statistics, 2009. CA Cancer J Clin. 2009;59(4):225-249.

2. Landis SH, Murray T, Bolden S, Wingo PA. Cancer statistics, 1998. CA Cancer J Clin. 1998;48(1):6-29.

3. Wisnivesky JP, Yankelevitz D, Henschke CI. Stage of lung cancer in relation to its size: Part 2. Evidence. Chest. 2005;127(4):1136-1139.

4. Hanna N, Shepherd FA, Fossella FV, et al. Randomized phase III trial of pemetrexed versus docetaxel in patients with non-small-cell lung cancer previously treated with chemotherapy. J Clin Oncol. 2004;22(9): $1589-1597$. 
5. Shepherd FA, Dancey J, Ramlau R, et al. Prospective randomized trial of docetaxel versus best supportive care in patients with non-small-cell lung cancer previously treated with platinum-based chemotherapy. J Clin Oncol. 2000;18(10):2095-2103.

6. Shepherd FA, Rodrigues Pereira J, Ciuleanu T, et al. Erlotinib in previously treated non-small-cell lung cancer. $N$ Engl J Med. 2005; 353(2):123-132.

7. Khan MI, Chesney JA, Laber DA, Miller DM. Digitalis, a targeted therapy for cancer? Am J Med Sci. 2009;337(5):355-359.

8. Newman RA, Yang P, Pawlus AD, Block KI. Cardiac glycosides as novel cancer therapeutic agents. Mol Interv. 2008;8(1):36-49.

9. Ramirez-Ortega M, Maldonado-Lagunas V, Melendez-Zajgla J, et al. Proliferation and apoptosis of HeLa cells induced by in vitro stimulation with digitalis. Eur J Pharmacol. 2006;534(1-3):71-76.

10. Kometiani P, Liu L, Askari A. Digitalis-induced signaling by $\mathrm{Na}^{+} /$ $\mathrm{K}^{+}$-ATPase in human breast cancer cells. Mol Pharmacol. 2005;67(3): 929-936.

11. Factor P, Senne C, Dumasius V, et al. Overexpression of the $\mathrm{Na}^{+}, \mathrm{K}^{+}$-ATPase alpha1 subunit increases $\mathrm{Na}^{+}, \mathrm{K}^{+}$-ATPase function in A549 cells. Am J Respir Cell Mol Biol. 1998;18(6):741-749.

12. Liu J, Tian J, Haas M, Shapiro JI, Askari A, Xie Z. Ouabain interaction with cardiac $\mathrm{Na}^{+} / \mathrm{K}^{+}$-ATPase initiates signal cascades independent of changes in intracellular $\mathrm{Na}^{+}$and $\mathrm{Ca}_{2}^{+}$concentrations. J Biol Chem. 2000;275(36):27838-27844.
13. Stenkvist B. Is digitalis a therapy for breast carcinoma? Oncol Rep. 1999;6(3):493-496.

14. Stenkvist B. Cardenolides and cancer. Anticancer Drugs. 2001;12(7): 635-638.

15. Stenkvist B, Bengtsson E, Eriksson O, Holmquist J, Nordin B, Westman-Naeser S. Cardiac glycosides and breast cancer. Lancet. 1979; 1(8115):563

16. Haux J, Klepp O, Spigset O, Tretli S. Digitoxin medication and cancer; case control and internal dose-response studies. BMC Cancer. $2001 ; 1: 11$

17. Simon R. Optimal two-stage designs for phase II clinical trials. Control Clin Trials. 1989;10(1):1-10.

18. Frese S, Frese-Schaper M, Andres AC, Miescher D, Zumkehr B, Schmid RA. Cardiac glycosides initiate Apo2L/TRAIL-induced apoptosis in non-small cell lung cancer cells by up-regulation of death receptors 4 and 5. Cancer Res. 2006;66(11):5867-5874.

19. Felth J, Rickardson L, Rosen J, et al. Cytotoxic effects of cardiac glycosides in colon cancer cells, alone and in combination with standard chemotherapeutic drugs. J Nat Prod. 2009;72(11):1969-1974.
Open Access Journal of Clinical Trials

\section{Publish your work in this journal}

The Open Access Journal of Clinical Trials is an international, peerreviewed, open access journal publishing original research, reports, editorials, reviews and commentaries on all aspects of clinical trial design, management, legal, ethical and regulatory issues, case record form design, data collection, quality assurance and data auditing

\section{Dovepress}

methodologies. The manuscript management system is completely online and includes a very quick and fair peer-review system, which is all easy to use. Visit http://www.dovepress.com/testimonials.php to read real quotes from published authors. 